\title{
Vascular Cell Adhesion Molecule-1 Is a Key Adhesion Molecule in Melanoma Cell Adhesion to the Leptomeninges
}

\author{
Dieta Brandsma, Jaap C. Reijneveld, Martin J. B. Taphoorn, Hetty C. de Boer, \\ Martijn F. B. G. Gebbink, Laurien H. Ulfman, Jaap-Jan Zwaginga, and \\ Emile E. Voest
}

Departments of Neurology (DB, JCR, MJBT), Medical Oncology (DB, JCR, HCdB, MFBGG, EEV), and Pulmonary Diseases (LHU), University Medical Center Utrecht, Utrecht, and Crucell (HCdB), Leiden, and Department of Hematology (J-JZ), Academical Medical Center and Sanquin Research at the Central Laboratory for Blood Transfusion, Amsterdam, The Netherlands

SUMMARY: Leptomeningeal metastases occur in up to $8 \%$ of patients with systemic malignancies and have a poor prognosis. A better understanding of the pathophysiologic processes underlying leptomeningeal metastases is needed for more effective treatment strategies. We hypothesized that tumor cells will have to adhere to the well-vascularized leptomeninges, because the cerebrospinal fluid lacks nutrients and growth factors for efficient tumor cell proliferation. Specific receptor-ligand interactions, which are unknown until now, will mediate this adhesion process. We determined the growth characteristics of B16F-10 melanoma cells in cerebrospinal fluid. The expression levels of specific adhesion molecules on both mouse leptomeningeal cells (MLMC) and murine B16F-10 melanoma cells were measured by immunofluorescence flow cytometry. We used mAbs to determine the function of these specific adhesion molecules on B16F-10 melanoma cell adhesion to a leptomeningeal cell layer under static and (cerebrospinal fluid-like) flow conditions. B16F-10 melanoma cells did not proliferate in cerebrospinal fluid because of a lack of nutrients and growth factors. MLMC expressed low levels of vascular cell adhesion molecule-1 (VCAM-1), intercellular adhesion molecule-1 (ICAM-1), $\beta_{1}$ - and $\beta_{3}$-integrin subunits, and CD44. VCAM-1 expression on MLMC was shown to be up-regulated by TNF- $\alpha$. Blocking VCAM-1 on the MLMC with a mAb resulted in a $60 \%$ inhibition of melanoma cell adhesion to a leptomeningeal cell layer under flow but not under static conditions. No additive inhibitory effect on melanoma cell adhesion was found by concomitant blocking of the $\beta_{1}$ - and $\beta_{3}$-integrin subunits and CD44 with mAbs. Our experiments indicate that cerebrospinal fluid does not support B16F-10 melanoma cell proliferation, suggesting the need for melanoma cell adhesion to the well-vascularized leptomeninges. VCAM-1, expressed on MLMC, is an important mediator of in vitro melanoma cell adhesion under (cerebrospinal fluid-like) flow conditions. (Lab Invest 2002, 82:1493-1502).

\begin{abstract}
T eptomeningeal metastases (LM) occur in 0.8 to $L_{8 \%}$ of cancer patients, most frequently originating from myeloproliferative tumors, melanoma, and breast and lung cancer. New developments in cancer treatment have led to a prolonged survival of patients with several types of cancer, including myeloproliferative tumors and breast carcinoma. Consequently, the incidence of metastatic complications, such as LM, is increasing. Survival of patients with LM is usually less than 6 months despite intrathecal chemotherapy and radiotherapy of symptomatic sites (DeAngelis, 1998; Posner, 1995). More knowledge about the pathophys-
\end{abstract}

\section{DOI: 10.1097/01.LAB.0000036876.08970.C1}

Received May 31, 2002.

This research was supported by grants from the Dutch Cancer Society (NKB to JCR and NKB 99-2114 to EEV and MFBGG) and the Dutch Organization for Scientific Research (NWO, reg. no. 920-03-075 to JCR and reg. no. 920-03-138 to DB).

Address reprint requests to: Prof. Dr. E. E. Voest, Department of Medical Oncology, University Medical Center Utrecht, P.O. Box 85500, 3508 GA Utrecht, The Netherlands.E-mail: E.E.Voest@azu.nl iologic processes may lead to treatment strategies that can improve the dismal outcome of LM.

LM can arise when tumor cells enter the subarachnoid space through direct growth of a tumor adjacent to the leptomeninges, via extravasation of tumor cells from the circulation, or when malignant cells spread via perineural spaces (Kokkoris, 1983; Mareel et al, 1998). The fate of tumor cells is unknown once they have reached the cerebrospinal fluid in the subarachnoid space. We hypothesized that cerebrospinal fluid lacks the nutrients and growth factors needed for tumor cell proliferation. Therefore, adhesion of tumor cells to the well-vascularized leptomeninges will be essential for further tumor growth. Histologic studies in the in vivo B16F-10 melanoma LM model cells indeed showed that tumor cells adhere to the leptomeninges in the early stages of LM (Reijneveld et al, 1999). Adhesion of tumor cells to surrounding cells or matrix proteins is mediated by cell surface adhesion molecules (Albelda, 1993; Zetter, 1993). These adhesion molecules are classified into several families, such as selectins, integrins, cad- 
herins, members of the immunoglobulin superfamily, and cell surface glycoproteins like CD44.

Adhesion molecules implicated in distant melanoma metastases include $\alpha_{\mathrm{v}} \beta_{3}$ integrin, binding vitronectin, and a wide range of other matrix proteins (Marshall and Hart, 1996; Nip and Brodt, 1995). Furthermore, a high expression of CD44 on melanoma cells has been associated with a high metastatic potential in an experimental animal model (Birch et al, 1991). Finally, the expression of $\alpha_{4} \beta_{1}$ integrin (very late antigen 4; VLA-4) on melanoma cells has shown to be crucial in distant melanoma metastases via its binding to vascular cell adhesion molecule-1 (VCAM-1), expressed on cytokine-activated (IL-1 and TNF- $\alpha$ ) endothelium (Dejana et al, 1988; Garofalo et al, 1995; Okahara et al, 1994; Rice et al, 1988; Rice and Bevilacqua, 1989). A comparison between melanoma cell adhesion to endothelium and leptomeninges may be envisioned, because in both situations melanoma cells have to adhere to mesenchyme-like cells under flow conditions (blood velocity in capillaries: $0.05-0.1 \mathrm{~cm} / \mathrm{sec}-$ onds [Whitmore, 1968]; cerebrospinal fluid velocity: 0-7 cm/seconds [Henry-Feugeas et al, 1993]). Until now, adhesion of tumor cells to the leptomeninges has only been studied by Giese et al (1998), who demonstrated that glioma cell adhesion to a human leptomeningeal cell layer under static conditions could be blocked by antibodies against the $\beta_{1}$ subunit. Immunohistochemical studies have additionally shown that CD44 and the $\beta_{1}$-integrin subunit are expressed on human leptomeninges (Beschet et al, 1999; FigarellaBranger et al, 1997) and that intercellular adhesion molecule-1 (ICAM-1; ligand: $\alpha_{\llcorner} \beta_{2}$ integrin) is expressed on normal and traumatized rat spinal cord leptomeninges (Isaksson et al, 1999).

In this study we demonstrate that B16F-10 melanoma cells do not proliferate in cerebrospinal fluid because of a lack of nutrients and growth factors, suggesting the need for tumor cell adhesion to the leptomeninges. We show that primary cultures of mouse leptomeningeal cells (MLMC) express low levels of VCAM-1, which can be up-regulated by TNF- $\alpha$. Using a newly developed in vitro adhesion model for LM, we provide evidence that VCAM-1 plays a key role in melanoma cell adhesion to a leptomeningeal cell layer under (cerebrospinal fluid-like) flow conditions.

\section{Results}

\section{Growth Characteristics of B16F-10 Melanoma Cells in Cerebrospinal Fluid}

B16F-10 melanoma cells had a doubling time of approximately 16 hours when cultured in DMEM containing 5\% fetal bovine serum (FBS). Doubling time diminished to 13 hours when cells were cultured in DMEM with $40 \%$ FBS (data not shown). The proliferation of B16F-10 melanoma cells decreased in a linear way when cells were cultured in medium with an increasing percentage of cerebrospinal fluid $(0 \rightarrow$ $100 \%$ ) and a decreasing percentage of DMEM supplemented with $40 \%$ FBS $(100 \rightarrow 0 \%)$ during 72 hours
(Fig. 1A). Interestingly, melanoma cells cultured in $100 \%$ cerebrospinal fluid hardly showed any proliferation, whereas no significant cell death occurred after 72 hours (trypan blue staining). The decreased cell proliferation in medium with increasing percentages of cerebrospinal fluid could be either a result of shortage of nutrients/growth factors in cerebrospinal fluid or of the presence of proliferation-inhibiting factors in the cerebrospinal fluid. To discriminate between these two factors, we cultured B16F-10 melanoma cells in medium containing 15\% DMEM, 5\% FBS, increasing amounts of cerebrospinal fluid (0\% to $40 \%$ to $80 \%$ of total culture medium) and decreasing amounts of saline ( $80 \%$ to $40 \%$ to $0 \%$ of culture medium). Addition of cerebrospinal fluid did not result in decreased proliferation compared with addition of saline to normal culture medium (Fig. 1B). This finding suggests that cerebrospinal fluid does not contain specific factors that inhibit proliferation, but rather a shortage of nutrients and growth factors in cerebrospinal fluid and saline causes the diminished cell tumor cell proliferation.

\section{Characteristics of Primary Culture of MLMC}

Primary cell cultures grew readily from leptomeningeal tissue that was carefully dissected from the brains of 2-day-old mice. The cells were pleomorphic: approximately $60 \%$ of the cells displayed a broadly polygonal shape with cytoplasmic arcs and the remaining cells were spindle shaped (Fig. 2A). They maintained their morphologic characteristics at confluence (Fig. 2B). The cell morphology was comparable with earlier described primary cultures of human leptomeningeal cells (DeGiorgio et al, 1994; Rutka et al, 1986). Immunohistochemical stainings demonstrated that more than $95 \%$ of the cultured cells were positive for vimentin, which is an intermediate filament expressed on normal human leptomeningeal tissue (Kartenbeck et al, 1984). Moreover, the immunofluorescent cell staining for von Willebrand factor was negative, and no platelet endothelial cellular adhesion molecule-1 (PECAM-1) expression was found on the MLMC by immunofluorescence flow cytometry (Fig. 3A), indicating the absence of contaminating endothelial cells in the primary culture.

\section{Identification of Cell Adhesion Molecules Present on MLMC and Murine B16F-10 Melanoma Cells}

To determine the expression of surface adhesion molecules on MLMC and B16F-10 melanoma cells, immunofluorescence flow cytometry was performed. MLMC expressed low levels of VCAM-1, ICAM- $1, \beta_{1}$ and $\beta_{3}$-integrin subunits, and CD44. No expression of $\beta_{2}$-integrin subunit, PECAM-1, L-selectin, and E-selectin was seen on MLMC (Fig. 3A, Table 1). No difference in expression levels of adhesion molecules was found between cells treated with trypsin during 2 minutes or with $10 \mathrm{~mm}$ EDTA $(\mathrm{pH}=7.5)$ during 5 minutes, except for the CD44 expression (mean fluorescence intensity $[\mathrm{MFI}]$ for trypsin treated cells $=16$ 
\pm 4 versus EDTA $=168 \pm 21)$. B16F-10 melanoma cells expressed the $\alpha_{4}$-integrin subunit, $\beta_{1}$ - and $\beta_{3}$ integrin subunits, and CD44. No expression of $\beta_{2}$ - and $\beta_{7}$-integrin subunits, VCAM-1, ICAM-1, L-selectin, and E-selectin was seen (Fig. 3B, Table 1). Again the CD44 expression level was higher on the cell surface of EDTA-treated B16F-10 melanoma cells (MFI $=72$ \pm 2 ) as compared with trypsin-treated cells (MFI = 32 \pm 9 ), without differences in expression levels of other adhesion molecules.

\section{VCAM-1 Expression on MLMC After TNF- $\alpha$ Activation}

Because VCAM-1 expression on endothelium is known to be up-regulated by cytokines like TNF- $\alpha$ (Rice and Bevilacqua, 1989), we determined whether VCAM-1 expression on MLMC can also be modified by TNF- $\alpha$. MLMC were activated with TNF- $\alpha$ (40 $\mathrm{ng} / \mathrm{ml}$ ) during 4,6 , and 16 hours, after which VCAM-1 expression was measured by FACS analysis. No significant up-regulation of VCAM-1 on MLMC was seen after 4 and 6 hours of TNF- $\alpha$ stimulation (data not shown). TNF- $\alpha$ activation of MLMC during 16 hours induced a $2.9 \pm 0.5$-fold increase of VCAM-1 expression on MLMC (mean \pm SEM; Fig. 4).

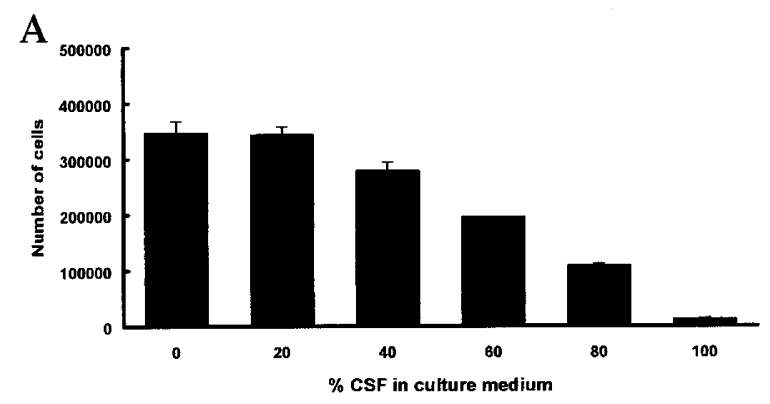

B

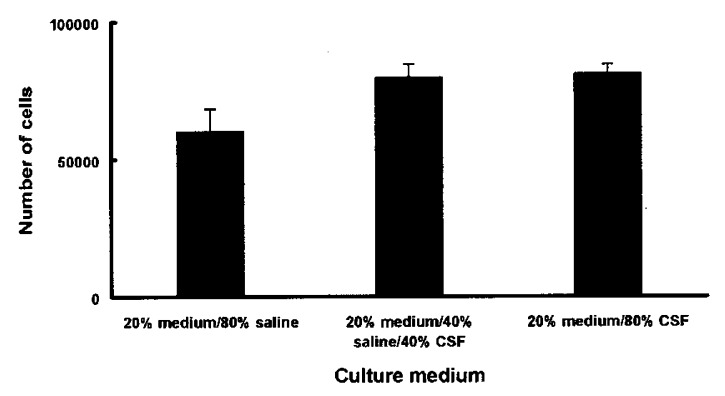

Figure 1.

A, Culture of B16F-10 melanoma cells in decreasing percentages of original culture medium (DMEM with $40 \%$ FBS) with increasing percentages of cerebrospinal fluid resulted in a decreased proliferation after 72 hours (bars represent mean \pm SEM). A significant decrease in proliferation was reached when $40 \%$ cerebrospinal fluid was added to the medium ( $n=3$; independent sample $t$ test: $p<0.05$ ). B, Addition of cerebrospinal fluid instead of saline to the culture medium (DMEM with $5 \% \mathrm{FBS}$ ) did not lead to a significant decrease of cell proliferation after 72 hours of cell culture. Bars show mean \pm SEM $(n=$ 3 ; independent sample $t$ test: $p>0.1$ ).
B16F-10 Melanoma Cell Adhesion Under Flow Conditions-Effect of B16F-10 Cell Concentration, Perfusion Time, and Shear Stress

Because tumor cells have to adhere to the leptomeninges under cerebrospinal fluid flow conditions (0-7 $\mathrm{cm} / \mathrm{seconds}$ ) (Henry-Feugeas et al, 1993), we used a modified form of a perfusion setup (Sakariassen et al, 1983) to determine B16F-10 melanoma cell adhesion to a leptomeningeal cell layer under flow conditions. The perfusion setup was validated by measuring the effect of B16F-10 cell concentration, time of perfusion, and shear stress on B16F-10 melanoma cell adhesion. Melanoma cell adhesion increased in a linear way using cell concentrations varying from $5 \times 10^{5}$ to $4 \times$ $10^{6} \mathrm{cells} / \mathrm{ml}$ (shear stress $=50 \mathrm{mPa}$; perfusion time $=$ 5 minutes). A cell concentration of $8 \times 10^{6} \mathrm{cells} / \mathrm{ml}$ did not further increase melanoma cell adhesion (Fig. 5A). Adhesion of melanoma cells increased in a linear way with perfusion times ranging from 5 to 20 minutes (50 $\mathrm{mPa} ; 4 \times 10^{6}$ melanoma cells $/ \mathrm{ml}$ ) (Fig. 5B). Cells started to spread on the leptomeningeal cell layer after 7.5 minutes. An inverse relation was seen between shear stress (50-250 mPa) and B16F-10 melanoma cell adhesion ( $4 \times 10^{6}$ melanoma cells $/ \mathrm{ml} ; 5$ minutes) (Fig. 5C). Shear forces did not induce rolling of the melanoma cells but rather a direct tethering followed by firm adhesion of the cells on the leptomeningeal cell layer.

\section{B16F-10 Melanoma Cell Adhesion Under Flow Conditions-Effect of mAbs Against VCAM-1, $\beta_{1}$ and $\beta_{3}$-Integrin Subunits, and CD44}

Based on the expression levels of adhesion molecules on MLMC and melanoma cells, measured by immunofluorescence flow cytometry and the known ligandreceptor interactions (Table 2), we evaluated the effect of mAbs against CD44, $\beta_{1}$ - and $\beta_{3}$-integrin subunits, and VCAM-1 on B16F-10 melanoma cell adhesion to a leptomeningeal cell layer under flow conditions $(1.0 \times$ $10^{6}$ cells $/ \mathrm{m}$; $50 \mathrm{mPa} ; 5$ minutes). MLMC also expressed ICAM-1, but no expression of its ligands $\left(\beta_{2}\right.$ integrins) was found on B16F-10 melanoma cells, so we did not test mAbs against ICAM-1. Melanoma cell adhesion under flow conditions was reduced by $60 \%$ after pretreatment of the leptomeningeal cell layer by an anti-VCAM-1 mAb as compared with an isotype-
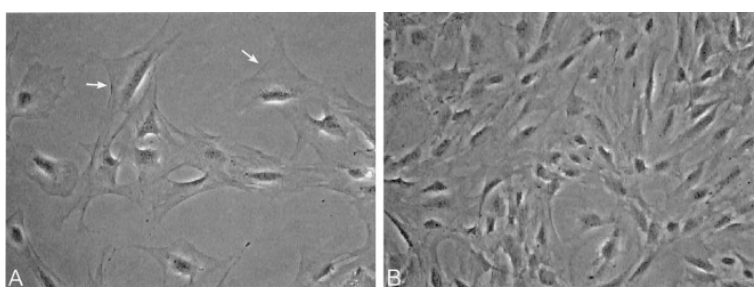

Figure 2.

A, Light microscopic photograph of the mouse leptomeningeal cell (MLMC) culture at Day 2 after isolation of leptomeningeal tissue showing polygonal cells with cytoplasmic arc structures (arrows). B, Light microscopic photograph of the MLMC culture at day 5 demonstrating the cobblestone-like appearance at confluence. 
matched control antibody (Fig. 6). No additive inhibitory effect on B16F-10 melanoma cell adhesion was seen when B16F-10 melanoma cells were also pretreated with a mixture of mAbs against $\beta_{1}$ - and $\beta_{3}$ integrin subunits and CD44 (Fig. 6). Furthermore, pretreatment of B16F-10 melanoma cells with single mAbs against either $\beta_{1}$ - or $\beta_{3}$-integrin subunits or CD44, without blockade of VCAM-1, did not result in a significant reduction of adhesion $\left(\beta_{1}\right.$-integrin subunit: $15 \%$ reduction $[n=3 ; p=0.2] ; \beta_{3}$-integrin subunit: $0 \%[n=3]$; CD44: $0 \%[n=3]$ (data not shown).

\section{B16F-10 Melanoma Cell Adhesion Under Static Conditions-Effect of mAbs Against VCAM-1, $\beta_{1}$ - and $\beta_{3}$-Integrin Subunits, and CD44}

We also evaluated the effect of mAbs against CD44, $\beta_{1}$ - and $\beta_{3}$-integrin subunits, and VCAM-1 on B16F-10 melanoma cell adhesion to a leptomeningeal cell layer under static conditions, because cerebrospinal fluid flow may be absent at some localizations in the subarachnoid space (cerebrospinal fluid flow 0-7 cm/ seconds) (Henry-Feugeas et al, 1993). Static B16F-10 melanoma cell adhesion during 30 minutes was not inhibited by pretreatment of leptomeningeal cells with anti-VCAM-1 nor by additional pretreatment of the B16F-10 melanoma cells with antibodies against $\beta_{1}$ and $\beta_{3}$-integrin subunits and CD44 (Fig. 7).

\section{Discussion}

For the first time, we demonstrate that tumor cells in cerebrospinal fluid do not proliferate because of a lack of nutrients and growth factors. This finding supports our hypothesis that tumor cell adhesion to the wellvascularized leptomeninges is needed for tumor cell proliferation. Earlier histologic studies of experimental LM showed that B16F-10 melanoma cell adhesion to the leptomeninges occurs in the early stage of LM, whereas in later stages larger well-vascularized tumor nodules were found (Reijneveld et al, 1999). Moreover, we have established that leukemia cell adhesion to the leptomeninges is crucial for the progression of leptomeningeal leukemia (JC Reijneveld et al, unpublished data). The reason why tumor cell adhesion to the leptomeninges would be so crucial in LM may be the efficient provision of nutrients and growth factors to the adhered tumor cells via the well-vascularized leptomeninges. Furthermore, the leptomeningeal cells themselves may provide survival and proliferation signals to the adhered tumor cells, a process called anchorage dependency (Ruoslahti, 1997; Schwartz, 1997).

Adhesion of tumor cells to the leptomeninges has to take place under cerebrospinal fluid flow conditions, with flow velocities varying from $0-7 \mathrm{~cm} /$ seconds, dependent on the localization in the subarachnoid space (Henry-Feugeas et al, 1993). In the underlying study we show that VCAM-1, expressed on primary cultures of murine leptomeningeal cells, plays a key role in B16F-10 melanoma cell adhesion to a leptomeningeal cell layer under (cerebrospinal fluid-like) flow conditions. Since B16F-10 melanoma cells express $\alpha_{4}$ - and $\beta_{1}$-integrin subunits and no $\beta_{7}$-integrin subunits, VCAM-1 on leptomeningeal cells interacts with $\alpha_{4} \beta_{1}$ integrin (VLA-4) on melanoma cells and not with the other identified VCAM-1 ligand, the $\alpha_{4} \beta_{7}$ integrin. We found that pretreatment of the leptomeningeal cells with an anti-VCAM-1 mAb led to a $60 \%$ inhibition of B16F-10 melanoma cell adhesion under flow conditions but not under static conditions. This strong reduction of melanoma cell adhesion under flow conditions by blocking VCAM-1 may be explained by the important role of the VCAM-1/NLA-4 interaction in the initial attachment of the B16F-10 melanoma cells with the leptomeningeal cell surface. VCAM-1 has been shown to support leukocyte tethering (=short transient interactions), rolling and rapid sticking, and arrest (Alon et al, 1995; Berlin et al, 1995), followed by firm adhesion, a process mediated by integrins (Butcher, 1991; Springer, 1994). An important role for VCAM-1/NLA-4 in the initial attachment of melanoma cells also explains the lack of effect of anti-VCAM-1 mAbs on B16F-10 melanoma cell adhesion under static conditions, since cell tethering can be overruled by firm adhesion during static cellcell interactions. Surprisingly, no additional inhibitory effect on melanoma cell adhesion under static and flow conditions was found by concomitant pretreatment of B16F-10 melanoma cells with mAbs against $\beta_{1}$ - and $\beta_{3}$-integrin subunits and CD44, molecules that are all important in firm adhesion. This lack of inhibitory effect under both conditions does not necessarily indicate that $\beta_{1}$ - and $\beta_{3}$-integrin subunits and CD44 are not important in firm adhesion of melanoma cells to the leptomeninges. Rather, these results may be explained by a redundancy of other, unknown adhesion molecules important in the adhesion process.

The crucial role for VCAM-1 in in vitro melanoma cell adhesion to the leptomeninges, found in this study, is comparable with its role in in vitro melanoma cell adhesion to the endothelium (Bertomeu et al, 1993; Dejana et al, 1988; Rice et al, 1988). Interestingly, VCAM-1/VLA-4 interaction mediating melanoma adhesion to endothelium was shown to be critically involved in in vivo melanoma lung metastasis (Garofalo et al, 1995; Okahara et al, 1994). Okahara et al (1994) found that TNF- $\alpha$ intravenously administered before B16-BL6 inoculation significantly enhanced pulmonary metastasis in C57BL6 mice. Pretreatment of the B16-BL6s cells with an anti-VLA-4 mAb or administration of an anti-VCAM-1 mAb abolished this enhancement. Similarly, IL-1-mediated augmentation of pulmonary metastasis of A375M melanoma cells in nude mice was completely abrogated by an antiVLA-4 mAb (Garofalo et al, 1995).

Our findings point to a model for LM in which VCAM-1 on leptomeningeal cells mediates tumor cell adhesion under cerebrospinal fluid flow conditions (Fig. 8). Tumor cells adhered to the well-vascularized leptomeninges start proliferating and ultimately form large-size tumor cell layers or nodules, which become dependent on angiogenesis (Reijneveld et al, 2002). In contrast, nonadhered cells in the cerebrospinal fluid 


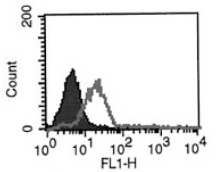

$\beta_{1}$ integrin

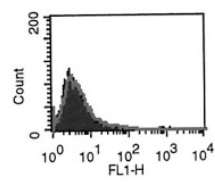

PECAM-1

B
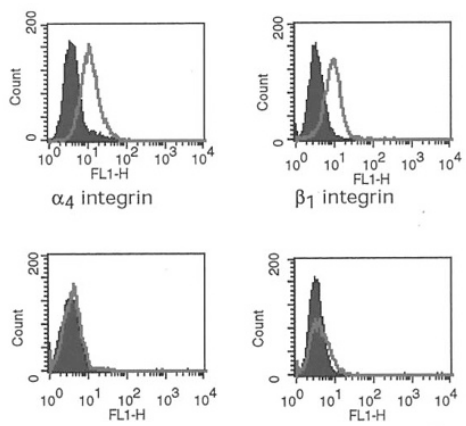

VCAM-1

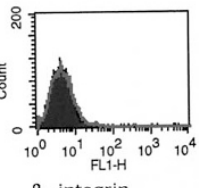

$\beta_{2}$ integrin

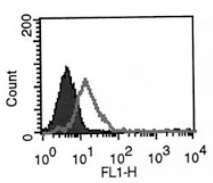

CD44

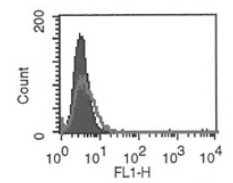

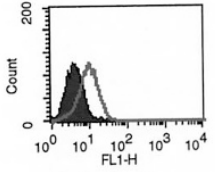

$\beta_{3}$ integrin

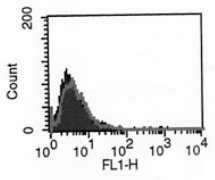

E-selectin

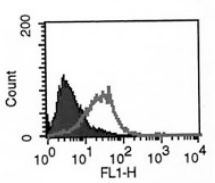

VCAM-1

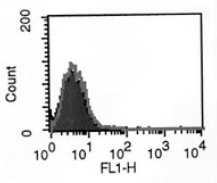

L-selectin

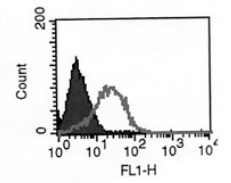

ICAM-1

murine B16F-10 melanoma cells
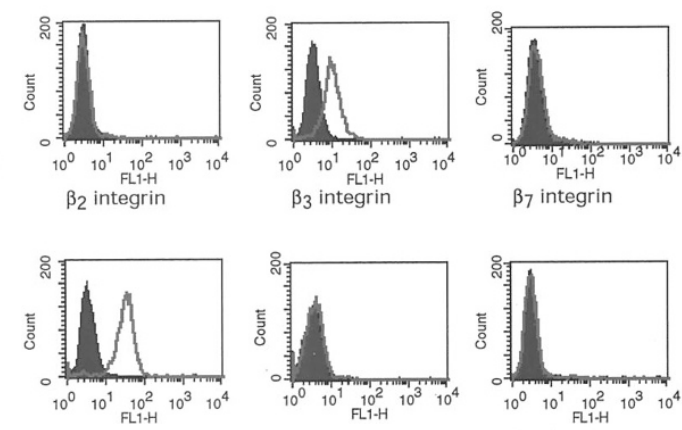

CD 44
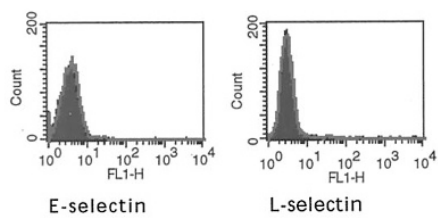

L-selectin

Figure 3.

FACS expression patterns of adhesion molecules on mouse leptomeningeal and murine B16F-10 melanoma cells. Open curves indicate FACS histogram plots of cells stained with a mAb against a specific adhesion molecule. Solid curves represent FACS histogram plots of cells stained with an isotype-matched antibody. MLMC express $\beta_{1}$ - and $\beta_{3}$-integrin subunits, CD44, VCAM-1, and ICAM-1. No expression of the $\beta_{2}$-integrin subunit, PECAM-1, L-selectin, and E-selectin was seen on the cell surface of leptomeningeal cells. B16F-10 melanoma cells express $\alpha_{4^{-}}, \beta_{1^{-}}$, and $\beta_{3^{-}}$-integrin subunits and CD44. No expression of $\beta_{2}$ - and $\beta_{7^{-}}$-integrin subunits, VCAM-1, ICAM-1, L-selectin, and E-selectin was seen on the cell surface of B16F-10 melanoma cells. One representative FACS experiment of three experiments performed in duplicate is plotted.

do not multiply because of a lack of nutrients and growth factors. TNF- $\alpha$, either produced by the tumor cells or macrophages entering the cerebrospinal fluid or systemically leaking in the cerebrospinal fluid, may facilitate this adhesion process via an up-regulation of VCAM-1 expression on the leptomeningeal cells. Immunocytochemical detection of TNF- $\alpha$ in tumor cells present in the cerebrospinal fluid in patients with LM (Nakamura et al, 1995) and high levels of TNF- $\alpha$ levels in the cerebrospinal fluid in children with central nervous system leukemia support this hypothesis (Ishii et al, 1991). Further research on the factors determining the process of tumor cell adhesion to the leptomeninges is in progress. This research may eventually direct the way to new prophylactic antiadhesive treatment strategies like anti-VCAM mAbs, intrathecally administered in patients with a high risk for LM, eg, patients who undergo surgery for a brain metastasis in the posterior fossa and consequently have an elevated risk of developing LM because of tumor cell shedding into the cerebrospinal fluid (van der Ree et al, 1999) and patients with acute lymphoblastic leukemia or high-grade non-Hodgkin's lymphoma currently receiving potential toxic, prophylactic intrathecal chemotherapy.

\section{Methods}

\section{Antibodies and Cytokines}

The following functional blocking mAbs were purchased from PharMingen (San Diego, California): purified rat monoclonal IgGs against mouse integrin $\alpha_{4}$ chain (CD49d; clone R1-2), mouse integrin $\beta_{1}$ chain (CD29; clone 9EG7), mouse integrin $\beta_{2}$ chain (CD18; clone GAME-46), mouse integrin $\beta_{7}$ chain (clone FIB27), mouse CD44 (clone KM114), mouse VCAM-1 (CD106; clone 429 [MVCAM.A]), mouse PECAM-1 (CD31; clone MEC 13.3), mouse E-selectin (CD62E; clone 10E9.6), and mouse L-selectin (CD62L; clone MEL-14), and purified hamster monoclonal IgGs against mouse ICAM-1 (CD54; clone 3E2) and mouse integrin $\beta_{3}$ chain (CD61; clone 2C9.G2). Furthermore, purified rat $\operatorname{lgG}_{1 \kappa}$ (clone R3-34), hamster $\operatorname{lgG}_{1}$ (clone G235-2356), and rat $\operatorname{lgG}_{2 \alpha}$ (clone R35-95) isotype control immunoglobulins and FITC-conjugated mouse anti-rat $\lg _{2 a}$ (clone G28-5) and anti-hamster $\operatorname{lgG}_{1 / 2 b}$ 
Table 1. Expression of Specific Adhesion Molecule Expression on Mouse Leptomeningeal Cells and Murine B16F-10 Melanoma Cells ${ }^{a}$

\begin{tabular}{|c|c|c|c|c|c|c|}
\hline \multirow[b]{3}{*}{ Adhesion molecule } & \multicolumn{6}{|c|}{ Mean fluorescence intensity } \\
\hline & \multicolumn{3}{|c|}{ Mouse leptomeningeal cells } & \multicolumn{3}{|c|}{ Murine B16F-10 melanoma cells } \\
\hline & $\begin{array}{l}\text { Specific adhesion } \\
\text { molecule }\end{array}$ & Isotype control & $p$ value & $\begin{array}{l}\text { Specific adhesion } \\
\text { molecule }\end{array}$ & Isotype control & $p$ value \\
\hline$\alpha_{4}$ integrin subunit & $6(2)$ & $5(0)$ & 0.0826 & $17(1)^{\star}$ & $6(0)$ & 0.0003 \\
\hline$\beta_{1}$-integrin subunit & $26(3)^{*}$ & $6(1)$ & 0.0011 & $19(5)^{*}$ & $5(0)$ & 0.0290 \\
\hline$\beta_{2}$-integrin subunit & $6(1)$ & $7(1)$ & 0.6026 & $4(0)$ & $4(0)$ & 0.1526 \\
\hline$\beta_{3}$-integrin subunit & $10(0)^{*}$ & $6(0)$ & 0.0001 & $11(1)^{*}$ & $6(1)$ & 0.0005 \\
\hline$\beta_{7}$-integrin subunit & $5(1)$ & $5(0)$ & 0.9886 & $5(0)$ & $5(0)$ & 0.1676 \\
\hline VCAM-1 & $19(4)^{\star}$ & $6(1)$ & 0.0134 & $5(0)$ & $5(0)$ & 0.1447 \\
\hline ICAM-1 & $28(1)^{\star}$ & $6(0)$ & 0.0000 & $6(1)$ & $6(1)$ & 0.6906 \\
\hline PECAM-1 & $5(0)$ & $6(1)$ & 0.4894 & Not tested & Not tested & \\
\hline CD44 & $16(2)^{*}$ & $9(1)$ & 0.0153 & $32(5)^{\star}$ & $4(1)$ & 0.0027 \\
\hline E-selectin & $6(1)$ & $6(1)$ & 0.8214 & $5(0)$ & $5(0)$ & 0.0707 \\
\hline L-selectin & $5(0)$ & $6(1)$ & 0.7201 & $5(1)$ & $5(0)$ & 0.3249 \\
\hline
\end{tabular}

${ }^{a}$ Measured by immunofluorescence flow cytometry after trypsin treatment. The mean fluorescent intensity ( \pm SEM) of the specific adhesion molecules and isotype controls of three experiments performed in duplicate is shown. Mean fluorescence intensities of specific adhesion molecules identified with asterisks are significantly higher than the isotype control values (independent sample $t$ test: $p<0.05$ ).

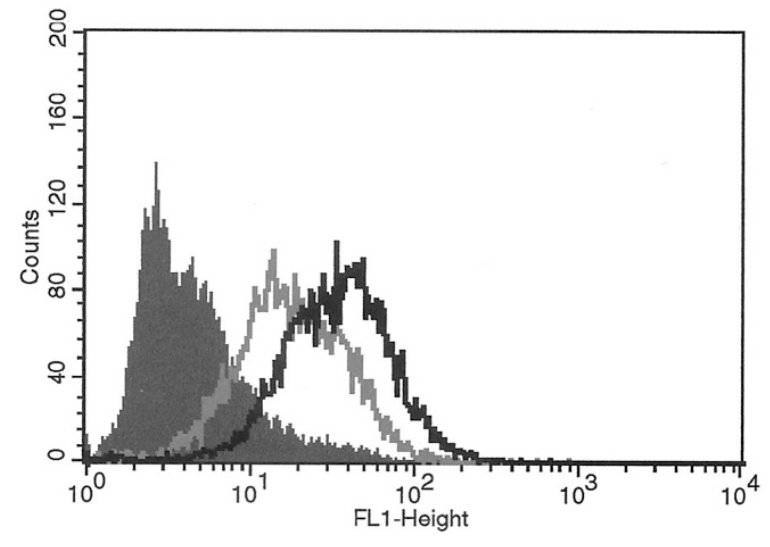

Figure 4.

VCAM-1 expression on MLMC after 16 hours of TNF- $\alpha$ stimulation, as determined by FACS analysis. The solid curve represents a FACS histogram plot of cells stained with an isotype-matched antibody. The gray, open curve shows the basal VCAM-1 expression on MLMCs, and the black, open curve demonstrates the VCAM-1 expression after 16 hours of TNF- $\alpha$ stimulation. One representative FACS experiment of four single experiments is plotted. The mean fold up-regulation of VCAM- 1 by 16 hours of TNF- $\alpha$ stimulation was 2.9 \pm 0.5 (mean \pm SEM; $n=4$; independent sample $t$ test: $p<0.05$ ).

(clones G70-204 and G94-56) were purchased from PharMingen. FITC-conjugated donkey anti-rat IgG $(\mathrm{H}+\mathrm{L})$ was obtained from Jackson ImmunoResearch (West Grove, Pennsylvania). Polyclonal rabbit antihuman von Willebrand factor, cross-reacting with mouse tissue, was purchased from Dako (Glostrup, Denmark). Peroxidase-conjugated swine anti-rabbit antibody was obtained from Dako. Recombinant human TNF- $\alpha$ was purchased from SanverTech (Heerhugowaard, The Netherlands).

\section{Reagents}

Tissue culture supplies (culture media, FBS, antibiotics, and trypsin) were obtained from GIBCO Biocult
(Grand Island, New York). Soybean trypsin inhibitor and DNase I were purchased from Sigma Chemical Company (St. Louis, Missouri). EDTA was obtained from Riedel de Haen (Seelze, Germany).

\section{MLMC}

MLMC were obtained through a modified protocol for the isolation of rat leptomeningeal cells (Ness and David, 1997). Briefly, leptomeninges were carefully dissected from the cortical surface of 2-day-old neonatal balb/c mice and trypsinized with $0.25 \%$ trypsin for 30 minutes at $37^{\circ} \mathrm{C}$. After neutralizing trypsin with DMEM containing $0.025 \%$ trypsin inhibitor and 0.004\% DNase I, cells were centrifuged (1250 rpm, 5 minutes, room temperature), resuspended, and plated in poly-L-lysine-coated plates. MLMC were cultured in DMEM containing sodium pyruvate and nonessential amino acids, supplemented with 10\% FBS, $1 \%$ penicillin/streptomycin/L-glutamine, and $0.1 \%$ amphotericin. Cells were incubated in 5\% $\mathrm{CO}_{2}-95 \%$ air at $37^{\circ} \mathrm{C}$ and passaged two or three times before use. Von Willebrand factor staining was performed, and PECAM-1 expression levels were measured to exclude a possible contamination with endothelial cells. Leptomeningeal cell layers for adhesion assays were obtained by administering $3.5 \times 10^{5}$ MLMC (400 $\mu$, $\left.8.75 \times 10^{6} \mathrm{cells} / \mathrm{ml}\right)$ in a meniscus on a poly-L-lysinecoated coverslip $(18 \times 18 \mathrm{~mm})$ in a 6 -well plate. After 20 minutes, $2 \mathrm{ml}$ of culture medium was added to the well. Two days later, confluent cell layers were used in the adhesion assays.

\section{Murine B16F-10 Melanoma Cells}

The murine B16F-10 melanoma cell line was originally obtained from I. J. Fidler (M.D. Anderson Cancer Center, Houston, Texas) (Fidler, 1975). Melanoma 
A

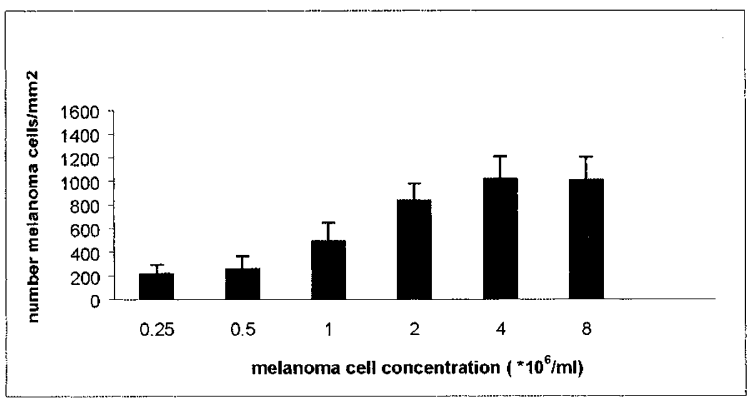

B

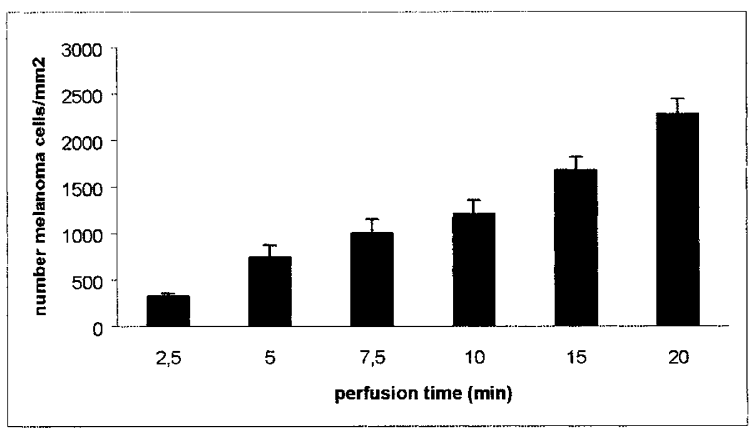

$\mathrm{C}$

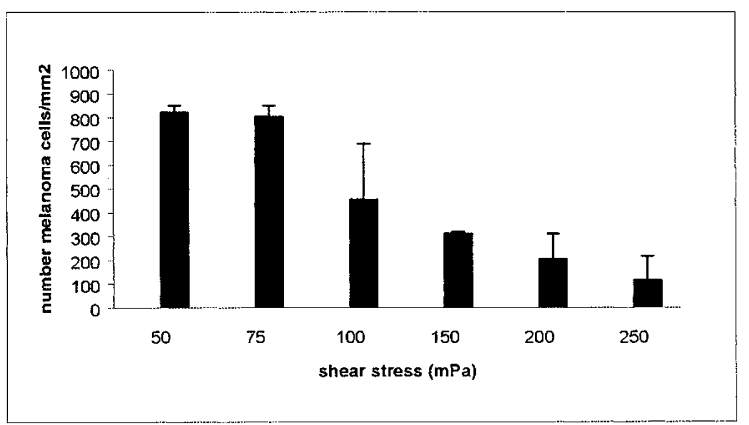

Figure 5.

B16F-10 melanoma cell adhesion to a leptomeningeal cell layer under flow conditions: effect of B16F-10 melanoma cell concentration $(A)$, perfusion time (B), and shear stress $(C)$. Number of adherent melanoma cells $/ \mathrm{mm}^{2}$ are plotted on the $y$ axis. A, Melanoma cell adhesion increased in a linear way using cell concentrations from $5 \times 10^{5}$ to $4 \times 10^{6} \mathrm{cells} / \mathrm{ml}$ ( $50 \mathrm{mPa}, 5$ minutes). Cell concentration of $8 \times 10^{6} \mathrm{cells} / \mathrm{ml}$ did not further increase melanoma cell adhesion. B, Adhesion of melanoma cells increased in a linear way with perfusion times ranging from 5 to 20 minutes ( $50 \mathrm{mPa} ; 4 \times 10^{6}$ melanoma cells $/ \mathrm{ml})$. C, An inverse relation was seen between shear stress $(50-250 \mathrm{mPa})$ and B16F-10 melanoma cell adhesion $\left(4 \times 10^{6}\right.$ melanoma cells $/ \mathrm{ml} ; 5$ minutes). Data represent the mean of three independent experiments \pm SEM.

cells were maintained as adherent monolayers in noncoated, plastic culture flasks in DMEM, supplemented with 5\% FBS and 1\% penicillin/streptomycin/ L-glutamine and incubated in 5\% $\mathrm{CO}_{2}-95 \%$ air at $37^{\circ} \mathrm{C}$. For adhesion assays, adherent melanoma cells were washed twice with PBS and incubated with trypsin at $37^{\circ} \mathrm{C}$ for 2 minutes. Trypsin was neutralized with serum-supplemented DMEM, and the detached cells were centrifuged (1500 rpm, 5 minutes, room temperature) and resuspended in DMEM supplemented with 1\% FCS and 1\% penicillin/streptomycin/ L-glutamine. B16F-10 melanoma cells cell counts were performed using a cell counter (Particle Counter; Coulter, Becton Dickinson, San Jose, California).

\section{Cerebrospinal Fluid}

Cerebrospinal fluid samples were obtained from patients with hydrocephalus or non-neurologic disease at the department of Neurology of the University Medical Center Utrecht, The Netherlands. Cell count and protein and glucose levels were within normal limits in these samples. Informed consent was obtained from these patients. The specimens were centrifuged at room temperature (10 minutes, $1250 \mathrm{rpm}$ ), and supernatants were immediately stored in polyethylene tubes at $-80^{\circ} \mathrm{C}$.

\section{Proliferation Assay}

For proliferation assays, B16F-10 melanoma cells were seeded in low density $\left(10^{4}\right.$ cells per well) in noncoated 24-well plates and cultured overnight. The next day, 8 to 12 randomly chosen wells were gently washed twice with PBS and incubated with trypsin (15 minutes, $\left.37^{\circ} \mathrm{C}\right)$. The cell suspension was transferred to $10 \mathrm{ml}$ of Isoton (Baker-Mallincrodt, Deventer, The Netherlands). The number of cells in each well was assessed using a cell counter (Particle Counter). The average of these counts was used as the number of cells per well at the start of the experiment $(t=0$ hours). Subsequently, wells were incubated with the selected culture medium ( $n=3$ per condition). After 72 hours, cell numbers were determined in the same way as at $\mathrm{t}=0$ hours. Vitality of the cells was determined by trypan blue staining.

\section{Immunofluorescence Flow Cytometry}

Expression of surface adhesion molecules was determined using immunofluorescence flow cytometry. Expression levels were measured after both trypsin and EDTA treatment, because trypsin is known to decrease the expression of adhesion molecules such as CD44 (Gardner et al, 1995). MLMC or B16F-10 melanoma cells were treated with trypsin (2 minutes) or with $10 \mathrm{~mm}$ EDTA ( $\mathrm{pH}=7.5,5$ minutes) and neutralized with DMEM supplemented with FBS, centrifuged, and washed twice in cold PBS $\left(4^{\circ} \mathrm{C}\right)$. Cells were resuspended in cold $\mathrm{PBS}$ supplemented with $1 \% \mathrm{BSA}$ $\left(4^{\circ} \mathrm{C}\right)$ and distributed in a concentration of 1 to $2 \times$ $10^{5}$ cells/sample in a 96-well plate. Cells were centrifuged (1250 rpm, 3 minutes, $4^{\circ} \mathrm{C}$ ) and incubated in 50 $\mu$ l of $1: 10$ diluted antibody in PBS/1\% BSA (60 minutes, $\left.4^{\circ} \mathrm{C}\right)$. Subsequently, cells were washed three times in PBS supplemented with $1 \%$ BSA $\left(4^{\circ} \mathrm{C}\right)$ and incubated in $50 \mu \mathrm{l}$ of 1:50 diluted, FITC-labeled, secondary antibody (30 minutes, $\left.4^{\circ} \mathrm{C}\right)$. After washing twice with $\mathrm{PBS} / 1 \% \mathrm{BSA}\left(4^{\circ} \mathrm{C}\right)$, stained cells were analyzed on a FACScalibur flow cytometer (Becton Dickinson, San Jose, California). Of each sample, forward scatter, side scatter, and fluorescence of $5 \times$ $10^{3}$ cells were recorded. Samples that were incubated with first step, isotype-matched, nonreactive antibodies in PBS/1\% BSA served as negative controls. The 
Table 2. Known Receptor-Ligand Interactions of Cell Surface Adhesion Molecules, of Which Expression Was Determined on B16F-10 Melanoma and Leptomeningeal Cells by FACS Analysis

\begin{tabular}{ll}
\hline Cell adhesion molecule (receptor) & \multicolumn{1}{c}{ Cell adhesion molecule (ligand) } \\
\hline VCAM-1 & $\alpha_{4} \beta_{1}$ integrin (VLA-4), $\alpha_{4} \beta_{7}$ integrin \\
$\alpha_{1} \beta_{1}-\alpha_{6} \beta_{1}$ integrins & Laminin, collagen, fibronectin \\
$\alpha_{4} \beta_{1}$ integrin (VLA-4) & VCAM-1, fibronectin \\
$\alpha_{v} \beta_{1}$ integrin & Fibronectin \\
$\alpha_{\mathrm{L}} \beta_{2}$ integrin (LFA-1) & ICAM-1 \\
$\alpha_{\mathrm{M}} \beta_{2}$ integrin (MAC-1) & ICAM-1 \\
$\alpha_{\mathrm{v}} \beta_{3}$ integrin & Vitronectin, fibrinogen, thrombospondin, von Willebrand's \\
& factor, fibronectin \\
CD44 & Hyaluronic acid \\
L-selectin & Sialyc acid, sialyl Lewis X and A, carbohydrate chains \\
E-selectin & Sialyl Lewis X and A, LECAM-1 \\
PECAM-1 & PECAM-1, Sialyl Lewis A \\
\hline
\end{tabular}

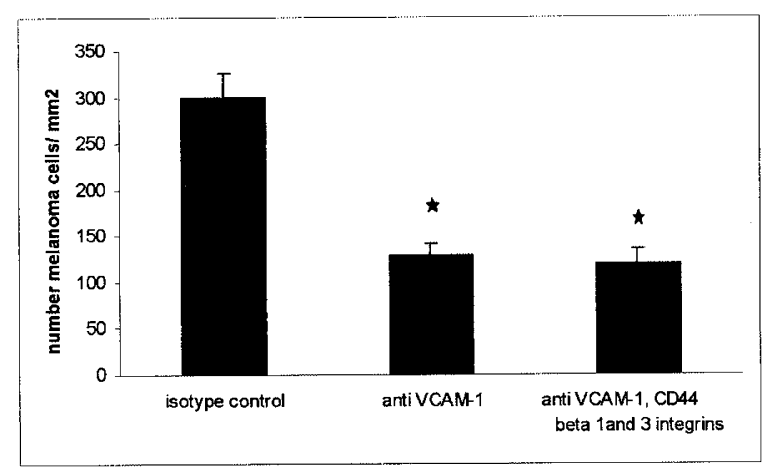

Figure 6.

Melanoma cell adhesion to a leptomeningeal cell layer under flow conditions: effect of blocking adhesion molecules with mAbs. The leptomeningeal cell layers were either incubated with isotype-matched control antibodies, antiVCAM-1, or anti-VCAM-1 and concomitant incubation of B16F-10 melanoma cells with mAbs against $\beta_{1}$ - and $\beta_{3}$-integrin subunits and CD44 $(10 \mu \mathrm{g} / \mathrm{ml})$ for 15 minutes at $37^{\circ} \mathrm{C}$. Melanoma cells $\left(10^{6}\right.$ cells $\left./ \mathrm{ml}\right)$ were perfused over a leptomeningeal cell layer for 5 minutes at shear stress $50 \mathrm{mPa}$, and the number of adhered melanoma cells $/ \mathrm{mm}^{2}$ was measured. Blocking VCAM- 1 on the leptomeningeal cell layer resulted into a $60 \%$ inhibition of melanoma cell adhesion under flow conditions as compared with the isotype-matched control (bar 2 versus bar $1 ; n=9$; independent sample $t$ test: $p<0.001$ ). No additive effect on melanoma cell adhesion was seen by also blocking $\beta_{1^{-}}$and $\beta_{3}$-integrin subunits and CD44 on the B16F-10 melanoma cells as compared with blocking VCAM-1 on the leptomeningeal cells alone (bar $3 ; n=9$; independent sample $t$ test: $p=0.7$ ).

adult aorta-derived mouse endothelial tumor cell line served as a positive control for E-selectin, VCAM-1, and PECAM-1 expression. The leukemia L1210 adherent subcell line, cultured in our laboratory, was used as a positive control for $\alpha_{4^{-}}, \beta_{1^{-}}$, and $\beta_{3}$-integrin subunit, CD44, and ICAM-1 expression. Mouse leukocytes served as positive controls for the expression of L-selectin and $\beta_{2}$ - and $\beta_{7}$-integrin subunits.

\section{In Vitro Tumor Cell Adhesion Model Under Flow Conditions}

Adhesion experiments under flow conditions were performed in a modified form of a transparent perfusion chamber (Sakariassen et al, 1983). The microchamber has a slit height of $0.2 \mathrm{~mm}$ and width of $2 \mathrm{~mm}$

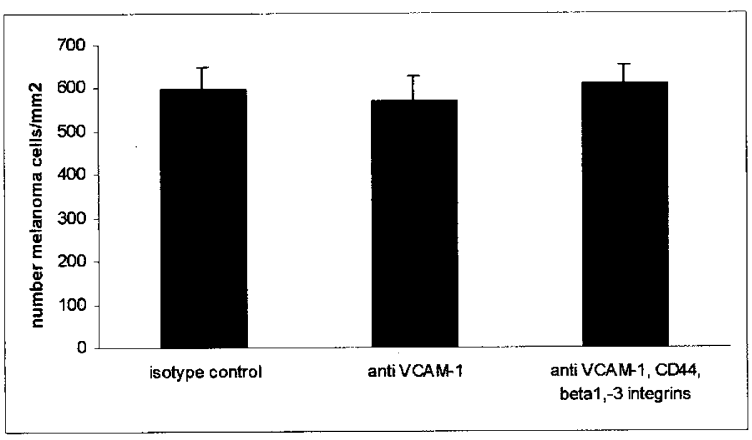

Figure 7.

Melanoma cell adhesion to a leptomeningeal cell layer under static conditions: effect of blocking adhesion molecules with mAbs. Leptomeningeal cell layers were either incubated with isotype-matched control antibodies, anti-VCAM-1, or anti-VCAM-1 and concomitant incubation of B16F-10 melanoma cells with mAbs against $\beta_{1}$ - and $\beta_{3}$-integrin subunits and CD44 (10 $\left.\mu \mathrm{g} / \mathrm{ml}\right)$ for 15 minutes at $37^{\circ} \mathrm{C}$. The mean number of melanoma cells on a leptomeningeal cell surface $\left(6.5 \mathrm{~mm}^{2}\right)$ after 30 minutes of static adhesion was measured. B16F-10 melanoma cell adhesion was not inhibited by pretreatment of leptomeningeal cells with anti-VCAM- 1 nor by additional pretreatment of the B16F-10 melanoma cells with antibodies against $\beta_{1}$ - and $\beta_{3}$-integrin subunits and CD44. The mean number of adhered melanoma cells $/ \mathrm{mm}^{2} \pm$ SEM of seven independent experiments was shown.

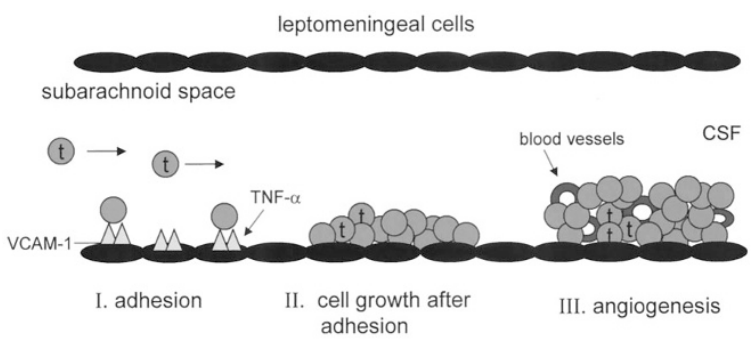

Figure 8.

Schematic model of the pathophysiologic processes in the cerebrospinal fluid in leptomeningeal metastases (LM). I. Tumor cells (t) enter the cerebrospinal fluid and move through the subarachnoid space under varying cerebrospinal fluid flow $(0-7 \mathrm{~cm} / \mathrm{seconds})$. Some of the tumor cells adhere to the leptomeningeal cells via receptor-ligand interactions between both cell types. II. Adhered tumor cells proliferate as a result of growth signaling induced by tumor cell adhesion to the leptomeninges and/or the provision of nutrients via the leptomeningeal vasculature. III. Large tumor nodules/layers are being formed, which become dependent on angiogenesis for further growth. $C S F=$ cerebrospinal fluid. 
and contains a plug on which a coverslip (18 $\mathrm{mm} \times 18$ $\mathrm{mm}$ ) with confluent leptomeningeal cells can be mounted. B16F-10 melanoma cells in suspension were aspirated from a reservoir through the perfusion chamber with a Harvard syringe pump (Harvard Apparatus, South Natic, Massachusetts). In this way, the flow rate through the chamber could be controlled precisely. The wall shear stress (t) was calculated from the equation: $\left.t=(6 Q \cdot \eta) / w \cdot h^{2}\right)$ in which $Q$ is the flow rate, $\eta$ is the suspending medium viscosity, $w$ is the slit width, and $h$ is the slit height. Shear stress was calculated in milli-Pascal. During the perfusion, the flow chamber was mounted on a microscope stage (DM RXE; Leica, Wetzlar, Germany), equipped with a B/W CCD-video camera (Sanyo, Osaka, Japan) coupled to a VHS video recorder. Perfusion experiments were recorded on videotape. Video images were analyzed for the number of adherent melanoma cells with a Quantimet 570C image-analysis system (Leica Cambridge, Cambridge, United Kingdom). The number of surface-adherent melanoma cells per square millimeter was measured after 5 minutes of perfusion at a minimum of 25 fields (total surface $\geq 1.0 \mathrm{~mm}^{2}$ ) using custom-made software developed in Optimas 6.1 (Media Cybernetics Systems, Silver Spring, Maryland). To determine the effect of blocking specific adhesion molecules on melanoma cell adhesion under flow conditions, B16F-10 melanoma cells and the leptomeningeal cell layer were preincubated with specific or isotype-matched control mAbs $(10 \mu \mathrm{g} / \mathrm{ml}, 15$ minutes at $37^{\circ} \mathrm{C}$ ).

\section{In Vitro Tumor Cell Adhesion Model Under Static Conditions}

For in vitro adhesion assays under static conditions, B16F-10 melanoma cells were washed with PBS, treated with trypsin $\left(37^{\circ} \mathrm{C}, 2\right.$ minutes), and neutralized with DMEM supplemented with FBS. Cells were centrifuged, washed with PBS again, and resuspended in DMEM without phenol red and sodium pyruvate (GIBCO Biocult) supplemented with 10\% FCS. B16F-10 melanoma cells were labeled with $0.5 \mu \mathrm{M}$ calcein (Molecular Probes, Leiden, the Netherlands; 5 minutes, $\left.37^{\circ} \mathrm{C}\right)$. After the labeling procedure, cells were centrifuged (1250 rpm, 5 minutes, room temperature) and resuspended in DMEM without phenol red and sodium pyruvate supplemented with 10\% FCS. Leptomeningeal cells and B16F-10 melanoma cells were incubated with specific or isotype-matched control antibodies $\left(10 \mu \mathrm{g} / \mathrm{ml}, 15\right.$ minutes, $\left.37^{\circ} \mathrm{C}\right)$. Static adhesion assays were performed by adding $4.0 \times 10^{5}$ fluorescently labeled, pretreated B16F-10 cells (>90\% viability) to a well containing a coverslip with a confluent pretreated leptomeningeal cell layer. After 30 minutes of adhesion, cells were washed three times with PBS and fixated with $2 \%$ paraformaldehyde. Five FITC images (1.3 $\mathrm{mm}^{2} /$ image) per coverslip were obtained of the central area of the leptomeningeal cell layer using a fluorescence microscope (Leica DM IRHC; Leica Microsystems BV, Rijswijk, The Netherlands). The confluence of the leptomeningeal cell layer was checked by light microscopy. The number of adherent B16F-10 melanoma cells per FITC image was determined by quantitative analysis using Leica WIN software (Leica Microsystems BV).

\section{Statistical Analysis}

Results of the adhesion assays are expressed as mean number of adherent cells \pm standard error of the mean (SEM). Statistical analysis of the data was performed using the independent sample Student's $t$ test. $p$ values $<0.05$ were considered to be significant.

\section{Acknowledgements}

We thank Ing. C. J. M. Aarsman, technician, Department of Medical Oncology, and Dr. S. Dijkstra and Prof. Dr. P. R. Bär, Research Laboratory of Neurology, University Medical Center Utrecht, for their help during the study. Furthermore, we express our gratitude to Prof. Dr. L. Koenderman and Dr. J. A. M. van der Linden, Department of Pulmonary Diseases, University Medical Center Utrecht, The Netherlands, and Mr. John F. Marshal, Imperial Cancer Research Fund Laboratories, London, for their valuable advice.

\section{References}

Albelda SM (1993). Role of integrins and other cell adhesion molecules in tumor progression and metastasis. Lab Invest 68:4-17.

Alon R, Kassner PD, Carr MW, Finger EB, Hemler ME, and Springer TA (1995). The integrin VLA-4 supports tethering and rolling in flow on VCAM-1. J Cell Biol 128:1243-1253.

Berlin C, Bargatze RF, Campbell JJ, von Andrian UH, Szabo MC, Hasslen SR, Nelson RD, Berg EL, Erlandsen SL, and Butcher EC (1995). Alpha 4 integrin mediate lymphocyte attachment and rolling under physiologic flow. Cell 80:413422.

Bertomeu MC, Gallo S, Lauri D, Haas TA, Orr FW, Bastida E, and Buchanan MR (1993). Interleukin 1-induced cancer cell/ endothelial cell adhesion in vitro and its relationship to metastasis in vivo: Role of vessel wall 13-HODE synthesis and integrin expression. Clin Exp Metastasis 11:243-250.

Beschet I, Brunon J, Scoazec JY, and Mosnier JF (1999). Expression of beta1 and beta4 integrins in normal arachnoid membrane and meningiomas. Cancer 86:2649-2658.

Birch M, Mitchell S, and Hart IR (1991). Isolation and characterization of human melanoma cell variants expressing high and low levels of CD44. Cancer Res 51:6660-6667.

Butcher EC (1991). Leukocyte-endothelial cell recognition: Three (or more) steps to specificity and diversity. Cell 67: 1033-1036.

DeAngelis LM (1998). Current diagnosis and treatment of leptomeningeal metastasis. J Neurooncol 38:245-252.

DeGiorgio LA, Sheu KF, and Blass JP (1994). Culture from human leptomeninges of cells containing neurofilament protein and neuron-specific enolase. J Neurol Sci 124:141-148.

Dejana E, Bertocchi F, Bortolami MC, Regonesi A, Tonta A, Breviario F, and Giavazzi R (1988). Interleukin 1 promotes tumor cell adhesion to cultured human endothelial cells. $\mathrm{J}$ Clin Invest 82:1466-1470. 
Fidler IJ (1975). Biological behavior of malignant melanoma cells correlated to their survival in vivo. Cancer Res 35:218224.

Figarella-Branger D, Roche PH, Daniel L, Dufour H, Bianco N, and Pellissier JF (1997). Cell-adhesion molecules in human meningiomas: Correlation with clinical and morphological data. Neuropathol Appl Neurobiol 23:113-122.

Gardner MJ, Jones LM, Catterall JB, and Turner GA (1995). Expression of cell adhesion molecules on ovarian tumour cell lines and mesothelial cells, in relation to ovarian cancer metastasis. Cancer Lett 91:229-234.

Garofalo A, Chirivi RG, Foglieni C, Pigott R, Mortarini R, Martin-Padura I, Anichini A, Gearing AJ, Sanchez-Madrid F, Dejana E, and Giavazzi R (1995). Involvement of the very late antigen 4 integrin on melanoma in interleukin 1-augmented experimental metastases. Cancer Res 55:414-419.

Giese A, Laube B, Zapf S, Mangold U, and Westphal M (1998). Glioma cell adhesion and migration on human brain sections. Anticancer Res 18:2435-2447.

Henry-Feugeas MC, Idy-Peretti I, Blanchet B, Hassine D, Zannoli G, and Schouman-Claeys E (1993). Temporal and spatial assessment of normal cerebrospinal fluid dynamics with MR imaging. Magn Reson Imaging 11:1107-1118.

Isaksson J, Farooque M, Holtz A, Hillered L, and Olsson $Y$ (1999). Expression of ICAM-1 and CD11b after experimental spinal cord injury in rats. J Neurotrauma 16:165-173.

Ishii E, Ohga S, Murano I, Kobayashi M, Kimura K, Eguchi H, Akazawa K, and Ueda K (1991). Tumor necrosis factor in the cerebrospinal fluid of children with central nervous system leukemia. Leuk Res 15:143-147.

Kartenbeck J, Schwechheimer K, Moll R, and Franke WW (1984). Attachment of vimentin filaments to desmosomal plaques in human meningiomal cells and arachnoidal tissue. J Cell Biol 98:1072-1081.

Kokkoris CP (1983). Leptomeningeal carcinomatosis: How does cancer reach the pia-arachnoid? Cancer 51:154-160.

Mareel M, Leroy A, and Bracke M (1998). Cellular and molecular mechanisms of metastasis as applied to carcinomatous meningitis. J Neurooncol 38:97-102.

Marshall JF and Hart IR (1996). The role of alpha v-integrins in tumour progression and metastasis. Semin Cancer Biol 7:129-138.

Nakamura S, Nagano I, Yoshioka M, Onodera J, Nakamura H, Shimazaki S, Tobita M, and Itoyama Y (1995). Immunocytochemical detection of tumor necrosis factor-alpha in infiltrating tumor cells in the cerebrospinal fluid from five patients with leptomeningeal carcinomatosis. Acta Neurol Scand 91: 137-140.

Ness R and David S (1997). Leptomeningeal cells modulate the neurite growth promoting properties of astrocytes in vitro. Glia 19:47-57.
Nip $\mathrm{J}$ and Brodt $P$ (1995). The role of the integrin vitronectin receptor, alpha $v$ beta 3 in melanoma metastasis. Cancer Metastasis Rev 14:241-252.

Okahara H, Yagita H, Miyake K, and Okumura K (1994). Involvement of very late activation antigen 4 (VLA-4) and vascular cell adhesion molecule 1 (VCAM-1) in tumor necrosis factor alpha enhancement of experimental metastasis. Cancer Res 54:3233-3236.

Posner J (1995). Neurological complications of cancer. Philadelphia: F. A. Davis Company.

Reijneveld JC, Taphoorn MJB, Kerckhaert OAJ, Drixler TA, Boogerd W, and Voest EE (In press, 2002). Angiostatin prolongs survival of mice with leptomeningeal metastases. Eur J Clin Invest.

Reijneveld JC, Taphoorn MJ, and Voest EE (1999). A simple mouse model for leptomeningeal metastases and repeated intrathecal therapy. J Neurooncol 42:137-142.

Rice GE and Bevilacqua MP (1989). An inducible endothelial cell surface glycoprotein mediates melanoma adhesion. Science 246:1303-1306.

Rice GE, Gimbrone MA Jr, and Bevilacqua MP (1988). Tumor cell-endothelial interactions: Increased adhesion of human melanoma cells to activated vascular endothelium. Am J Pathol 133:204-210.

Ruoslahti E (1997). Stretching is good for a cell. Science 276:1345-1346.

Rutka JT, Giblin J, Dougherty DV, McCulloch JR, DeArmond SJ, and Rosenblum ML (1986). An ultrastructural and immunocytochemical analysis of leptomeningeal and meningioma cultures. J Neuropathol Exp Neurol 45:285-303.

Sakariassen KS, Aarts PA, de Groot PG, Houdijk WP, and Sixma JJ (1983). A perfusion chamber developed to investigate platelet interaction in flowing blood with human vessel wall cells, their extracellular matrix, and purified components. $\mathrm{J}$ Lab Clin Med 102:522-535.

Schwartz MA (1997). Integrins, oncogenes, and anchorage independence. J Cell Biol 139:575-578.

Springer TA (1994). Traffic signals for lymphocyte recirculation and leukocyte emigration: The multistep paradigm. Cell 76:301-314.

van der Ree TC, Dippel DW, Avezaat CJ, Sillevis Smitt PA, Vecht CJ, and van den Bent MJ (1999). Leptomeningeal metastasis after surgical resection of brain metastases. J Neurol Neurosurg Psychiatry 66:225-227.

Whitmore RI (1968). Rheology of the circulation. Oxford: Pergamon Press.

Zetter BR (1993). Adhesion molecules in tumor metastasis. Semin Cancer Biol 4:219-229. 